\title{
Current Status of Urological Surgery Clinical Trials in the Middle East and Its Analysis in Comparison to Global
}

\author{
Orta Doğu'da Yürütülen Ürolojik Cerrahi Klinik Çalışmaların Bugünki Durumu ve Globale \\ Kıyasla Analizi
}

\author{
(1) Fatih Özdener ${ }^{1}$, (1) Alihan Sursal2, (1) Fehmi Narter ${ }^{3}$ \\ ${ }^{1}$ Bahçeşehir University Faculty of Medicine, Department of Pharmacology, İstanbul, Turkiye \\ ${ }^{2}$ Bahçeşehir University Faculty of Medicine, Department of Neuroscience, Istanbul, Turkiye \\ ${ }^{3}$ Acıbadem Mehmet Ali Aydınlar University Faculty of Medicine, Department of Urological Surgery, Istanbul, Turkiye
}

\section{What's known on the subject? and What does the study add?}

Importance of clinical trials upon evaluating novel therapeutic and diagnostic technologies is known. Trials targeting novel methods of urological surgery is equally crucial. However, vast majority of urological surgery clinical trials are progressing in North America and Europe, which indicates the opportunity and necessity upon implementing clinical trials in other regions such as the Middle East.

\begin{abstract}
Objective: To analyze the rates and types of ongoing urological surgery clinical trials (CTs) in the Middle East (ME) and worldwide.

Materials and Methods: The number of urological surgery CTs was identified via the ClinicalTrials.gov database. Studies were further analyzed using different filters present in ClinicalTrials.gov.

Results: Vast majority of urological surgery CTs are progressing in North America and Europe with 71.53\%. The ME accounts for only 6.19\%. In the

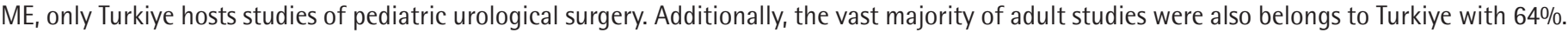
Further, the large portion of conducted CTs in the ME is phase 3 studies and studies with no phase indicated. Similarly, all urological surgery CTs conducted in Turkiye are in later phases or with no phase indicated. Moreover, industry resources are not directed upon these studies in the ME. Few countries use the advantages of industry resources for conducting urological surgery CTs.

Conclusion: The ME should be considered as a fertile land for adopting urological surgery CTs due to high population despite low ongoing studies. The lack of industry support in the ME is another problem, which may improve via rendering the ME more attractive for sponsors by adopting new regulatory guidelines for some of the countries.
\end{abstract}

Keywords: Urological surgery, Clinical trials, Middle East, Urology, Urology industry

Öz

Amaç: Ürolojik cerrahi klinik çalışmaların (CT) tipleri ve sayıları açısından Dünya'daki ve Orta Doğu'daki (OD) dağılımlarını incelemektir.

Gereç ve Yöntem: Bu CT'lerin dağılımları ClinicalTrials.gov sitesi kullanılarak analiz edildi. Ortaya çıkan bilgiler sitede bulunan filtreleme seçenekleri kullanılarak daha detaylı bir şekilde araştırıldı.

Bulgular: Ürolojik cerrahi CT'lerin \%71,53'ü Kuzey Amerika ve Avrupa'da görülürken, OD Bölgesi bu çalışmaların sadece \%6,19'unu oluşturmaktadır. Buna ek olarak, OD'deki pediyatrik çalışmaların hepsinin Türkiye'ye ait olduğu ortaya çıkmıştır. Ayrıca, Türkiye'de yürütülen ürolojik cerrahi CT'ler, OD'de yürütülen çalışmaların \%64'ünü oluşturmaktadır. Başka bir konu ise, OD'de yürütülen CT'lerin büyük bir çoğunluğunu faz 3 çalışmalarının ve fazı belirtilmeyen çalışmaların oluşturmasıdır. Buna benzer şekilde, Türkiye'deki çalışmaların hepsi geç fazlara ait veya fazı belirtilmeyen çalışmalardır. OD Bölgesi'nde endüstri sermayesi ile yürütülen çalışmaların sayısı birkaç ülke dışında yok denecek kadar azdır.

Sonuç: OD Bölgesi ürolojik cerrahi CT'leri yürütmek açısından verimli bir bölge olarak düşünülebilir. Bu bölgedeki hızla artan nüfus ve bununla doğru orantılı olarak ürolojik hastalıklardaki yaygınlık, yürütülen çalışmaların sayısı ile uyumululuk göstermemektedir. Az sayıdaki birkaç ülke hariç

Correspondence: Fatih Özdener MD, Bahçeșehir University Faculty of Medicine, Department of Pharmacology, İstanbul, Turkiye E-mail: fatih.ozdener@med.bau.edu.tr ORCID-ID: orcid.org/0000-0002-0163-318X

Received: 21.03.2019 Accepted: 08.04.2019

Cite this article as: Özdener F, Sursal A, Narter F. Current Status of Urological Surgery Clinical Trials in the Middle East and Its Analysis in Comparison to Global. J Urol Surg 2019;6(4):266-272.

- Copyright 2019 by the Association of Urological Surgery / Journal of Urological Surgery published by Galenos Publishing House. 
bu bölgede endüstri sermayesinin klinik çalışmalar lehine kullanılmaması da başka bir problemdir. Bu sorun OD Bölgesi'ni sponsorlar açısından daha cazip kılacak standartlar benimsenerek düzeltilebilir.

Anahtar Kelimeler: Ürolojik cerrahi, Klinik çalışmalar, Orta Doğu, Üroloji, İlaç endüstrisi

\section{Introduction}

Urological diseases are worldwide health problems composed of numerous complications, which require resource-rich surgical developments in order to increase life quality of patients and to prevent irreversible problems. Among them, renal stone formation is a growing urological disease with approximately $12 \%$ widespread prevalence. Kidney stone formation (urolithiasis) is directly proportional with redundant problematic mineral and protein intake with insufficient liquid consumption $(1,2)$. Poor awareness and unconscious consuming increase the probability of diseases not only in underdeveloped countries but also in developed countries. However, development of noninvasive or less invasive solutions targeting many urological conditions reduces the morbidity of procedures by replacing them (3). Robotic surgery is taking the place of traditional surgery in urological procedures as well as other procedures. Prostatectomy, cystectomy, pyeloplasty, nephrectomy and laparoscopic procedures can be handled with robotic technology with the benefits of lower blood loss and low surgical morbidity (4). These indicate the importance of clinical trials (CTs) upon new developments.

Results of metaanalysis studies on distribution and prevalence of urological diseases show that urolithiasis and renal infection are the most common disorders encountered in this category. When the same distribution observed in aged populations, prostate cancer, bladder cancer, lower urinary tract syndromes (generally in older men), urinary incontinence and urinary tract infections (generally in older woman) are conspicuous (3). Overall, metabolic syndromes increase the risk of urological diseases, which may evolve to end-stage renal diseases. Thus, surgical CTs serve as crucial tools of information to develop appropriate procedures and engineered constructs for implants. Controlled CTs of new drugs and surgical techniques are crucial in lowering the both morbidity of the procedure and mortality of the disease. Low susceptibility and funding opportunities in some underdeveloped countries generate a handicap upon adopting new CTs. Numerous governments reduce their funding towards clinical developments (3).

Despite the probable reasons and prevalence of urological diseases in specific regions are discussed in numerous studies, there is a lack of knowledge about the distribution of performed or ongoing clinical studies about urological surgery in these regions $(5,6,7,8,9,10,11,12,13,14)$. Ongoing CTs in the Middle East (ME) is not well established. Thus, we investigated the distributions of urological surgery CTs in the ME and globally by focusing different aspects such as number of pediatric or adult studies, sources of funding, and phases of the studies. Turkiye and Israel are the only countries, which host a small portion of CTs in urological surgery compared to North America and Europe. Despite high child population in the ME, pediatric CTs in urological surgery is dramaticly low as only Turkiye hosts pediatric CTs in the ME (15). The ME is a fertile land for organizing new CTs including pediatric studies of urological surgery with relatively low clinical studies compared to the prevalence of urological diseases and the population.

\section{Materials and Methods}

\section{Research of Clinical Trials Per Region from the ClinicalTrials. gov Database}

ClinicalTrials.gov database is the world's most comprehensive registry of CTs with 298.505 studies in 208 countries (16). The site became publicly available in 2000 and was containing only National Institutes of Health (NIH) funded studies until the participation of privately funded studies (17). By the aid of ClinicalTrials.gov, we revealed the distribution of urological surgery CTs worldwide alongside with detailed analysis over the ME considering phase of the study, type of funder, studied age group, country and region. Regions were selected according to registered CTs in ClinicalTrials.gov database. Scanning of urological surgery based CTs were operated during the first quarter of 2019. Ethical approval is not required for this study. This study does not include any patient.

\section{Database Search Criteria}

Utilizing advanced filtering available in ClinicalTrials.gov database, medical conditions themed as "urological surgery" were analyzed (e.g. nephrectomy, ureterostomy). For the children-based evaluation, the age group 0-17 was focused. For adult-based analysis, the age group was selected as $17+$. Both genders were included in this study. Among study types, observational studies together with interventional studies were included in database analysis. Studies were not filtered according to their provision upon medical improvements thus, studies without results were also included during filtering. Some important filtering involves the type of funding (e.g. industryfunded, other funded) and the current phase of the study (e.g. early phase through phase 4 and without phase). Worldwide analysis involves North America, Europe, East Asia, ME, South 
America, Pacifica, Africa, Southeast Asia, North Asia, South Asia and Central America. ME-specific analysis involves Turkiye, Israel, Lebanon, and Islamic Republic of Iran with studies at any rate.

\section{Results}

The first analysis includes the worldwide distribution of CTs on urological surgery. Among all urological surgery CTs, 71.53\% belongs to North America and Europe (37.37\% with 151 studies and $34.16 \%$ with 138 studies of the total of 404 , respectively). Other regions of the world forms only $28.47 \%$ of all studies (115 of 404) including the ME region with 6.19\% (25 of 404), which ranks the ME fourth following North America, Europe and East Asia, respectively (Figure 1). When the ME solely observed, $92.59 \%$ of all urological surgery clinical studies are progressing in Turkiye and Israel (66.67\% with 18 studies and 25.93\% with 7 studies of the total of 27 respectively) (Figure 2).

The second analysis involves the population-based distribution (child and adult) of urological surgery CTs in globally and the

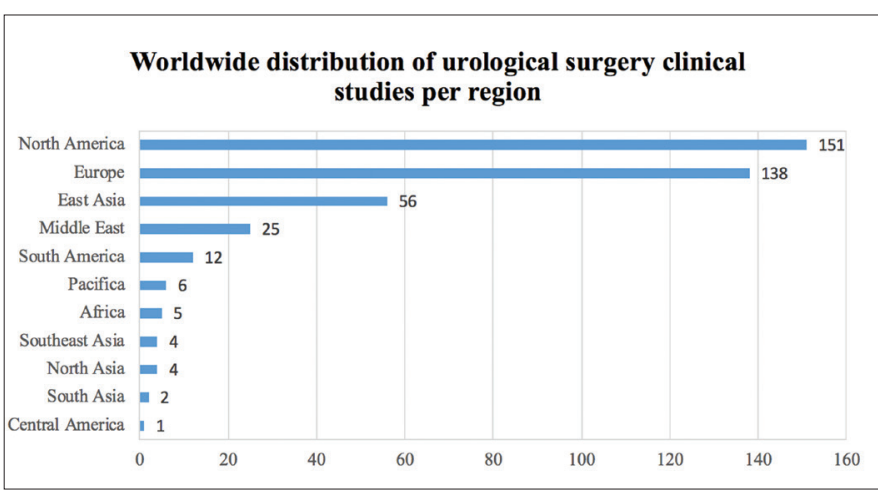

Figure 1. ClinicalTrials.gov database was investigated by using the keyword "urological surgery" in the condition or disease field. All age groups were globally examined via ClinicalTrial.gov database and separated according to geographical regions

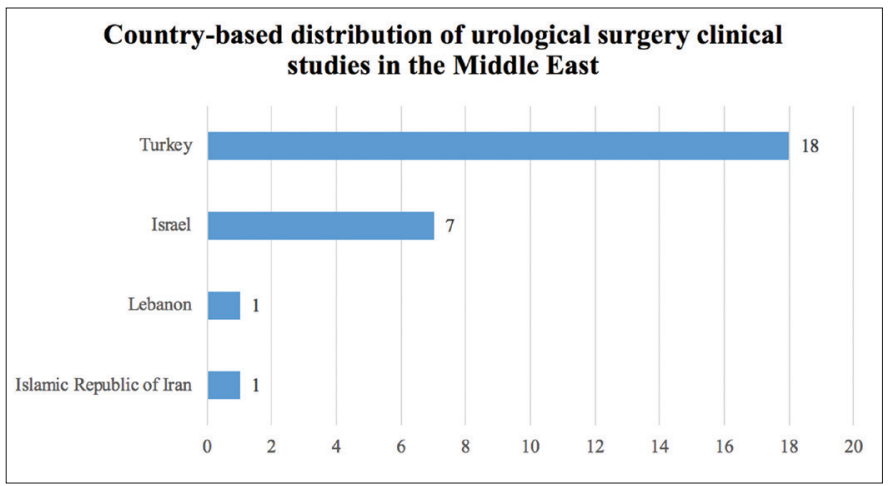

Figure 2. ClinicalTrials.gov database was investigated by using the keyword "urological surgery" in the condition or disease field. All age groups were examined via ClinicalTrial.gov database and separated according to countries forming the Middle East
ME. When observed globally, $14.16 \%$ of all urological CTs are pediatric studies (66 of 466) (Figure 3). When the ME solely observed, Turkiye has 100\% of conducted pediatric urological surgery CTs alongside with 64\% of adult studies (Figure 4).

The third analysis involves the phase distributions of urological surgery CTs globally and in the ME (Figure 5). The global distribution of study phases shows that only developed countries host initial phase (early phases, phase 1, phase 2) clinical studies. However, worldwide distribution of early phase clinical studies about urological surgery is few in number. Moreover, the regional phase distribution of CTs in the ME was also analyzed, which exhibits the lack of initial phase CTs in Turkiye. In the $M E$, Israel and Lebanon have only four conducted studies in initial phases despite zero studies at initial phases conducted in Turkiye and Iran (Figure 6).

Next, funding patterns upon urological surgery clinical studies

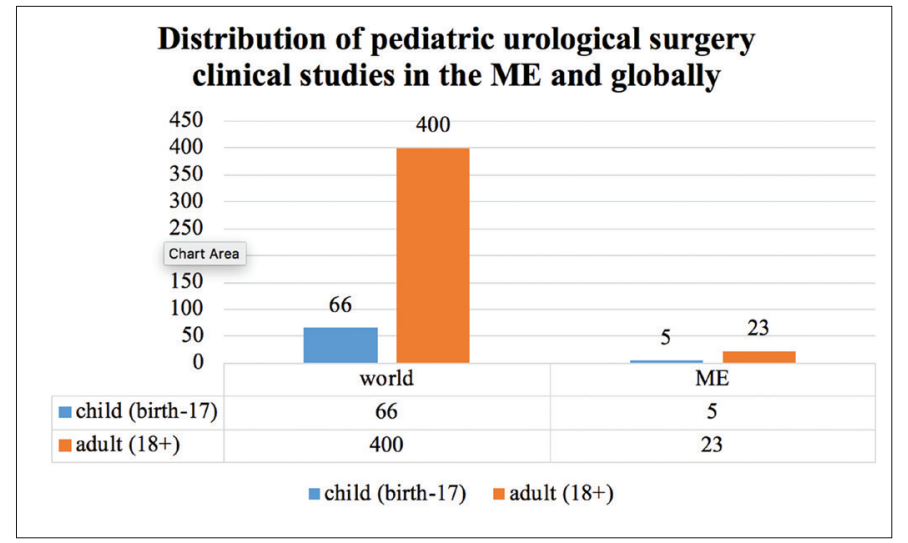

Figure 3. ClinicalTrials.gov database was investigated by using the keyword "urological surgery" in the condition or disease field. Age group $>17$ was selected for adult clinical studies and age group from birth to 17 were selected as pediatric clinical studies. Both adult and pediatric clinical studies were analyzed globally and compared with the middle east, ME: Middle East

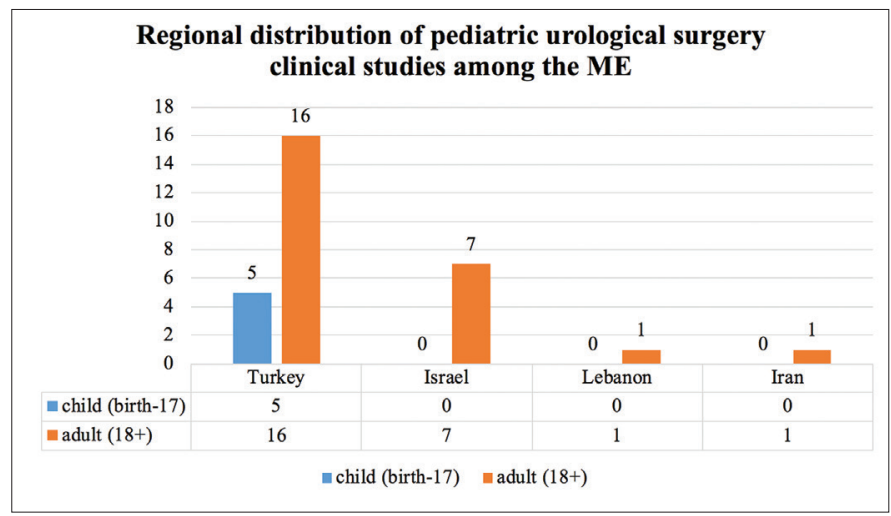

Figure 4. ClinicalTrials.gov database was investigated by using the keyword "urological surgery" in the condition or disease field. Age group $>17$ was selected for adult clinical studies and age group from birth to 17 were selected as pediatric clinical studies. Both adult and pediatric clinical studies were analyzed and compared according to countries forming the middle east, ME: Middle East 
were analyzed globally and in the ME. Worldwide industry funding for clinical studies of urological surgery is low. Industryfunded studies form only $12.53 \%$ of all urological surgery CTs (Figure 7). When the ME is solely observed, Israel stands out from all other regions despite small number of conducted urological CTs by taking the advantage of industry funds with $57 \%$ industry-funded studies (4 industry-funded and 3 other funded studies). Except regions without industry funded studies, Turkiye has a large difference between the industry funded-studies and all those funded by other funders; only $5.67 \%$ of urological surgery clinical studies was funded by industry against all other funders (Figure 8).

\section{Discussion}

Epidemiological studies indicates a global increment in urological diseases (5). The risk of urolithiasis increased from $3.2 \%$ to $8.8 \%$ in 3 years in the USA $(6,7)$. Specific increase in the incidence of a certain disease also depends on the region. (8).

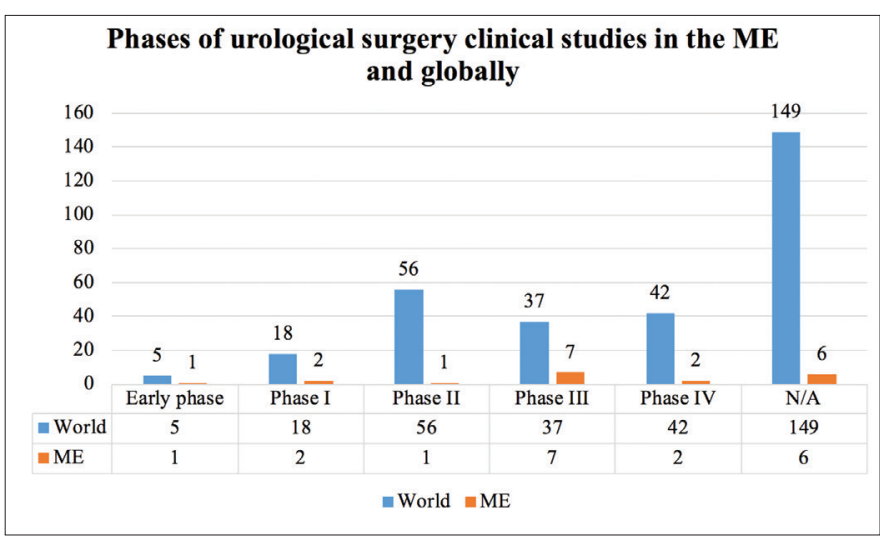

Figure 5. ClinicalTrials.gov database was investigated by using the keyword "urological surgery" in the condition or disease field. Search was conducted according to worldwide distribution of phases of urological surgery clinical trials initially. Then results were compared with the same distributions among the middle east, ME: Middle East

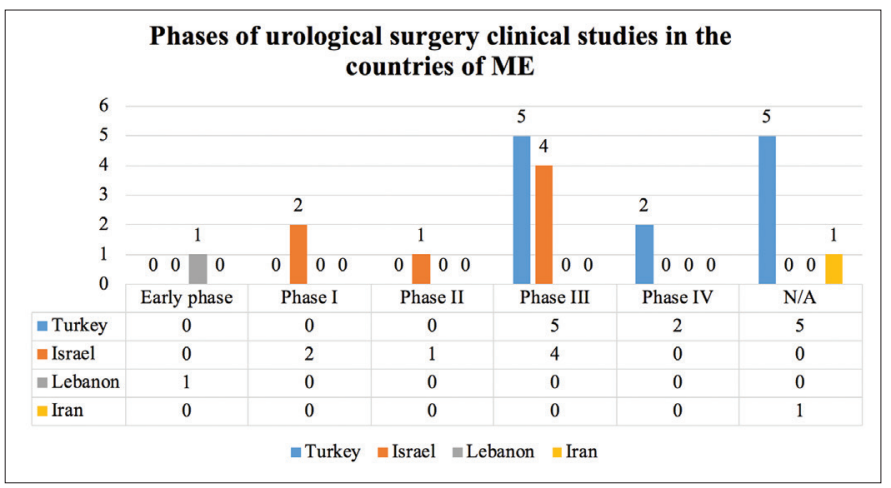

Figure 6. ClinicalTrials.gov database was investigated by using the keyword "urological surgery" in the condition or disease field. Search was conducted according to country-based distribution of phases of urological surgery clinical trials among the middle east, ME: Middle East
Hot and dry climates invoke the risk of acidic urine and finally urinary tract infection $(8,9)$. Thus, recent knowledge about the regional distribution of urological disease plays an important role in evaluating the clinical situation and availability. Region based registration data from the study performed in 2006 indicates that urological diseases caused approximately 830.000 deaths per year worldwide, which ranks them $12^{\text {th }}$ among all deaths (10). In South Africa, high cost and insufficient access to dialysis and kidney transplants abandon numerous patients with low social income to death (11).

Another study draws attention to incidence and mortality rates of kidney cancer over 39 countries. In contrary to general, developed countries have higher incidence and mortality rates compared to developing or underdeveloped countries (18). Nevertheless, when the incidence-to-mortality ratio is examined, a remarkable result emerged. Incidence-to-mortality ratio indicates the rate of death among patients with kidney cancer. The highest incidence-to-mortality ratio belongs to North America despite high incidence rate, which may be

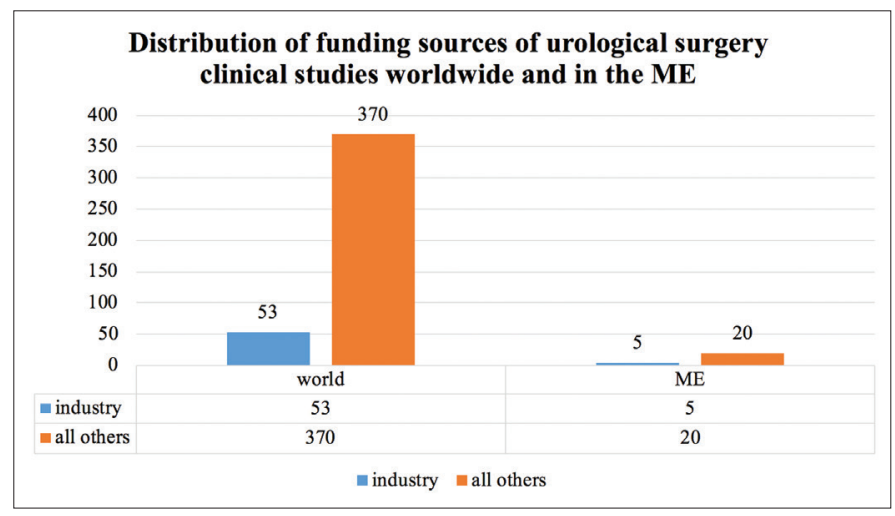

Figure 7. ClinicalTrials.gov database was investigated by using the keyword "urological surgery" in the condition or disease field. Search criteria is based on global distribution of industry funded studies versus all other funded studies. Then results were compared with the same examination among countries forming the middle east, ME: Middle East

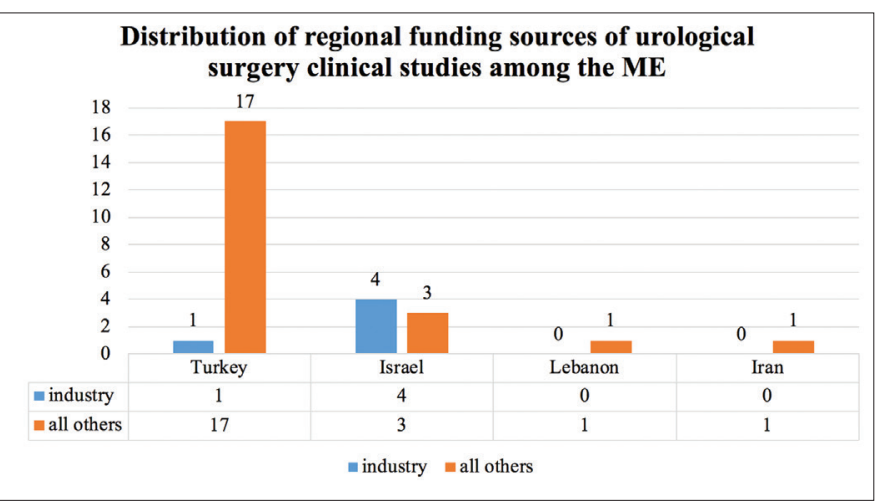

Figure 8. ClinicalTrials.gov database was investigated by using the keyword "urological surgery" in the condition or disease field. Search criteria is based on country-based distribution of industry funded studies versus all other funded studies the middle east, ME: Middle East 
directly proportional to socio-economic status of people, the emphasis of clinical developments and reserving resources upon these CTs while Africa has the lowest incidence-to-mortality ratio. These results indicate that in Africa, mortality rate of kidney cancer is $80 \%$, which is nearly fourfold higher compared to North America with 22.27\%.

These data indicates the need for availability of new CTs in urological surgery in the ME and other developing regions. However, lack of awareness of the importance of conducting CTs and lack of knowledge about the processes are major problems, which also cause trust issues (19). Information about the relevance of specific diseases among population, Good Clinical Practice (GCP) regulations, procedures during approval, awareness about the importance of CTs and available sites are one of the most important feasibilities during conducting studies (20). There is a higher risk of urological diseases in underdeveloped countries (10) in comparison to developed countries that show a higher risk of other diseases such as cancer, diabetes and obesity (18). So, we investigated the distribution of urological surgery CTs globally and in the ME from ClinicalTrials. gov. Despite the rapid increase in population and mortality, the ME ranks fourth in conducting urological CTs and only accounts for $6.19 \%$ of all urological surgery CTs conducted globally. North America and Europe forms $71.53 \%$ of all urological surgery CTs. The increase in pharma market in the regions of the ME and North Africa (MENA) as well as growth in sales market, indicates the potential towards adopting CTs $(15,19)$. We further analyzed the region-specific distribution of urological surgery CTs in the ME. Regions except Israel and Turkiye are in critical condition and only have two studies.

When we evaluated the distribution of pediatric CTs of urological surgery versus adult, we noticed that only $14.2 \%$ of all urological surgery studies were pediatric in the world (66 studies among 466 total). This low ratio of pediatric studies for the world is also observable for the ME region. Only, 17.9\% of all urological surgery studies were pediatric (five studies among 28 total). Despite the number of conducted studies in the ME is significantly lower compared to North America and Europe, the relative proportion of pediatric studies is similar when compared to global. We further investigated the regional distribution of pediatric studies among the ME region. Unfortunately, we observed that only Turkiye is adopting pediatric studies about urological surgery. All five pediatric studies belong to Turkiye in the ME. Thus, Turkiye maintains a similar rate of pediatric studies versus adult when compared with the global distribution. Even Israel lacks a single pediatric study despite the comparable number of conducted adult studies with Turkiye. The overall low number of pediatric studies about urological surgery may be explained with the prevalence, since pediatric urological disorders are less common when compared to adults $(3,21)$.
However, one of the highest percentage of young population resides in the ME region (15). Therefore, when the low socioeconomic status of countries in the ME region is taken into account, the proportion of pediatric urological disorders is expected to be higher.

Analysis of the phases of urological surgery CTs worldwide show that only a few studies are early phase studies followed in increasing order by phase 1, 2, 3, 4 and studies. Except four studies at initial phases adopted by Israel and Lebanon, all studies conducted in the ME are studies of later phases. This indicates another difference between developed and developing countries since only developed countries host studies of initial phases. Initial developmental phases of studies forges the foundations of novel developments but not mainly require high numbers of voluntary participants (22). Thence, inventor countries prefer adopting initial phases of studies in their countries. This could be the reason for lack of initial phase studies in developing countries as the rate of clinical upgrades adopted in developed countries are directly proportional with the distribution of CTs in these countries (Figure 1). Thus, when great numbers of voluntary participants are required for succession of late phase CTs, developing countries also start to be attractive. According to a study, the economical suitability is another reason, which renders developing countries attractive for conducting late CTs (23).

Nearly one quarter of the Investigational New Drug studies in the United States (US) requires results from other regions. Researchers from exterior regions are increasing in number due to lack of patient recruitment in developed countries such as Europe and US (20). Despite their main role of conducting new studies worldwide, there is a mandatory lag phase due to the impossibility of conducting clinical studies without enrolling required patients from the patient pool, which pushes sponsors to assess new CTs by targeting developing regions, such as the ME, Africa, South America and Asia, more than the developed countries (20). Despite the pecuniary opportunities, increase in the size of pharma market, and large patient pool in the developing countries, challenges upon the process of conducting CTs due to the regulatory reasons appear to be problematic and time consuming (24). That is why the feasibility of CTs are crucial on directing a study as the probable challenges and precautions can be taken to prevent inefficient work. Moreover, feasibility information creates a feedback about the oncoming results of the study. Generating information about CT feasibilities is the result of proper awareness and networking. Unfortunately, large portion of CT sites belongs to developed countries (15). In regions lacking proper CT networking, the information about the feasibilities become more valuable as the knowledge of regional and institutional applications helps estimate the completion time of a conducted study. If the required trust is obtained by sponsors based on the current 
performance of the study, targeting of developing countries for conduction of new clinical studies will be facilitated. Based on these criteria, to make a region more targetable for new CTs, adoption of International Conference on Harmonization (ICH) GCP guidelines, and by improving current regulations that cause delays in CT conduct are crucial (25). Globalization of GCP and awareness of CTs will surely upgrade the regulations of related countries upon managing new CTs, thus rendering problematic regions with unnecessary regulations more attractive to sponsors. Among the regions in the ME, Turkiye and Israel are prominent countries not only in urological surgery CTs but also in other subjects such as nutrition CTs and that the involvement of the ICH-GCP is directly proportional with the presence of CTs (15). Accepting the ICH-GCP in other regions of the ME should be restorative upon low CT capacity. Overall, the globalization of $\mathrm{GCP}$ and networking in developing countries are complementary with both the patient demand of developed countries and local advances in clinical studies. As a result, novel methods will be tested and approved more rapidly and efficiently as well as worldwide attainability will be a glimmer of hope for numerous hopeless patients.

Sponsorship and funding form the foundations of a study. Unfortunately, in the case of medical companies, generally funding is directly linked to profit. However, the NIH provides possibilities among the cooperation between for-profit and public services. Despite challenges in the MENA region, NIH researchers cooperates with local partners in order to discuss concerns and benefits due to significant prevalence of diseases in the MENA region (26). Therefore, a tripartite agreement, which is both beneficial to for-profit organizations, academicians and eventually public, should be forged. When the concerns of both for-profit organizations and academicians are in the same direction, performances of related studies increase. Therefore, we investigated both the worldwide distribution of fund providers and regional distribution of funders in the ME. We created two perspectives among the types of funding, industryfunded studies as the general source of for-profit enterprises and other funded studies. Worldwide distribution of industryfunded versus other funded studies shows that, industry only fund $12.5 \%$ of all CTs of urological surgery (53 studies among 423 total). When the ME region is solely investigated, there is no significant difference between the rate of other funded and industry-funded studies as only $20 \%$ of all CTs of urological surgery were maintained by industry support ( 5 studies among 25 total). However, the number of conducted studies is very limited in the ME region, which was previously underlined during investigating the sole distribution of urological surgery CTs. Next, we investigated the regional distribution of fund sources of urological surgery CTs in the ME region. Vast majority of industry funded-studies belongs to Israel with four studies versus only one industry funded-study conducted in Turkiye.
To sum up, as expected, the vast majority of conducted urological surgery CTs belongs to North America and Europe. In contrary to the increasing population and prevalence of urological disorders in the ME region, the number of related clinical studies remains critical. Worse is large portion of assessed studies are found in Turkiye and Israel, which renders remaining regions critical upon health management. Assessment of pediatric studies is also critical in the ME. Only Turkiye is adopting pediatric studies of urological surgery among the countries of the ME. Industry funding forms the smaller portion of ongoing studies worldwide except Israel. Turkiye is taking the attention with highest assessed studies compared to other regions of the ME.

\section{Study Limitations}

Outside of the wide scope of ClinicalTrials.gov, there are numerous unregistered studies, which renders the alternative data sources important (15). Other articles also refer the presence of unregistered trials with a percentage that cannot be ignored $(27,28)$. Moreover, some registered studies may escape advanced filtering due to unclear or incomplete reporting. Although distribution of the knowledge is dependent on the extent of a disease, the main cause of this problem is the potential of the funding institution. According to a database screening, industry-funded trails were more common compared to non-profit-funded studies (29). However, thumping majority of clinical studies can be found in ClinicalTrials.gov database.

\section{Conclusion}

The prevalence of urological disorders and related mortality in the developing or underdeveloped regions are higher due to low health awareness. Additionally, rapid increase in population of these regions is directly proportional with the rates of incidences. Regions in the ME lack suitable amount of urological surgery CTs and CTs in other therapeutic areas when compared with population, rendering these regions as a fertile land for conducting new studies. Thus, utilization of this opportunity can be beneficial for researchers, public and industry.

\section{Ethics}

Ethics Committee Approval: Ethical approval is not required for this study.

Informed Consent: This study does not include any patient.

Peer-review: Externally peer-reviewed.

\section{Authorship Contributions}

Concept: F.Ö., F.N., Design: F.Ö., F.N., Data Collection or Processing: F.Ö., Analysis or Interpretation: F.Ö., F.N., A.S., Literature Search: F.Ö, Writing: F.Ö. 
Conflict of Interest: No conflict of interest was declared by the authors.

Financial Disclosure: The authors declare that they have no relevant financial.

\section{References}

1. Alelign T, Petros B. Kidney Stone Disease: An Update on Current Concepts. Adv Urol 2018;2018:3068365.

2. Y. S. Alghamdi S, M. A. Alamri A, A. M. Alzahrani R. Awareness about Symptoms and Role of Diet in Renal Stones among General Population of Albaha City. The Egyptian Journal of Hospital Medicine 2018;70:50-59.

3. Abrams P, Wein A. Recent advances: urology. BMJ 2000;321:1393-1396.

4. Murphy D, Challacombe B, Khan MS, Dasgupta P. Robotic technology in urology. Postgrad Med J 2006;82:743-747.

5. Romero V, Akpinar H, G Assimos D. Kidney Stones: A Global Picture of Prevalence, Incidence, and Associated Risk Factors. Rev Urol 2010;12:e8696.

6. Stamatelou KK, Francis ME, Jones CA, Nyberg LM, Curhan GC. Time trends in reported prevalence of kidney stones in the United States: 1976-1994. Kidney Int 2003;63:1817-1823.

7. Scales CD, Smith AC, Hanley JM, Saigal CS. Prevalence of kidney stones in the United States. Eur Urol 2012;62:160-165.

8. Robertson WG. Stone formation in the Middle Eastern Gulf States: A review. Arab J Urol 2012;10:265-272.

9. Shields-Cutler RR, Crowley JR, Hung CS, Stapleton AE, Aldrich CC, Marschall J, Henderson JP. Human Urinary Composition Controls Antibacterial Activity of Siderocalin. J Biol Chem 2015;290:15949-15960.

10. Mathers CD, Lopez AD, Murray CJL. The Burden of Disease and Mortality by Condition: Data, Methods, and Results for 2001. In: Lopez AD, Mathers CD, Ezzati M, Jamison DT, Murray CJL, editors. Global Burden of Disease and Risk Factors. Washington (DC): World BankThe International Bank for Reconstruction and Development/The World Bank Group; 2006.

11. Dirks JH, Levin NW. Dialysis rationing in South Africa: A global message Kidney Int 2006;70:982-984.

12. Hostetter TH. Chronic kidney disease predicts cardiovascular disease. N Eng J Med 2004;351:1344-1346.

13. King $H$, Aubert RE, Herman WH. Global burden of diabetes, 19952025: prevalence, numerical estimates, and projections. Diabetes Care 1998:21:1414-1431.
14. Arrellano-Valdez F, Urrutia-Osorio M, Arroyo C, Soto-Vega E. A comprehensive review of urologic complications in patients with diabetes. Springerplus 2014;3:549.

15. Ozdener $F$, Kirbiyik $F$, Dogan AE. Analysis of nutrition clinical studies involving children in the Middle East and globally. Future Sci OA 2018;4:334.

16. National Library of Medicine. ClinicalTrials.gov 2019, February 27. Available from: https://clinicaltrials.gov/ct2/home.

17. Huser V, Cimino JJ. Linking ClinicalTrials.gov and PubMed to track results of interventional human clinical trials. PLoS One 2013;8:e68409-e.

18. Wong MCS, Goggins WB, Yip BHK, Fung FDH, Leung C, Fang Y, Wong SYS, $\mathrm{Ng}$ CF. Incidence and mortality of kidney cancer: temporal patterns and global trends in 39 countries. Sci Rep 2017;7:15698.

19. Erdogan B, Seker O, Chin LV. Regulations and Recruitment: Experiences in the Middle East. Journal for clinical studies 2017;9.

20. Rajadhyaksha V. Conducting feasibilities in clinical trials: an investment to ensure a good study. Perspect Clin Res 2010;1:106-109.

21. Robson WL, Leung AK, Boag GS. Common Pediatric Urological Disorders: Clinical and radiological evaluation. Can Fam Physician 1991;37:889-900.

22. Hay M, Thomas DW, Craighead JL, Economides C, Rosenthal J. Clinical development success rates for investigational drugs. Nat Biotechnol 2014;32:40-51.

23. Glickman SW, McHutchison JG, Peterson ED, Cairns CB, Harrington RA, Califf RM, Schulman KA. Ethical and scientific implications of the globalization of clinical research. N Engl J Med 2009;360:816-823.

24. Getz KA, Wenger J, Campo RA, Seguine ES, Kaitin KI. Assessing the impact of protocol design changes on clinical trial performance. Am J Ther 2008:15:450-457.

25. Dixon JR. The International Conference on Harmonization Good Clinical Practice guideline. Qual Assur 1998;6:65-74.

26. Tierney WM, Meslin EM, Kroenke K. Industry Support of Medical Research: Important Opportunity or Treacherous Pitfall? J Gen Intern Med 2016;31:228-233

27. Guo SW, Evers JL. Lack of transparency of clinical trials on endometriosis. Obstet Gynecol 2013;121:1281-1290.

28. Roberto A, Radrezza S, Mosconi P. Transparency in ovarian cancer clinical trial results: ClinicalTrials.gov versus PubMed, Embase and Google scholar. $J$ Ovarian Res 2018;11:28.

29. Zwierzyna $M$, Davies $M$, Hingorani $A D$, Hunter J. Clinical trial design and dissemination: comprehensive analysis of clinicaltrials.gov and PubMed data since 2005. BMJ 2018:361:k2130. 